\title{
Computational fluid dynamics in the assessment of patients' postoperative status after glottis-widening surgery
}

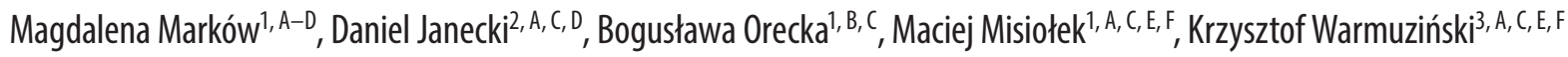 \\ ${ }^{1}$ Department of Otorhinolaryngology and Laryngological Oncology in Zabrze, Medical University of Silesia, Katowice, Poland \\ ${ }^{2}$ Department of Process Engineering, University of Opole, Poland \\ ${ }^{3}$ Institute of Chemical Engineering, Polish Academy of Sciences, Gliwice, Poland \\ A - research concept and design; $\mathrm{B}$ - collection and/or assembly of data; $\mathrm{C}$ - data analysis and interpretation; \\ $D$ - writing the article; $E$ - critical revision of the article; $F$ - final approval of article
}

Address for correspondence

Magdalena Marków

E-mail:magdalena.markow@gmail.com

Funding sources

None declared

Conflict of interest

None declared

Received on April 29, 2015

Revised on August 19, 2015

Accepted on January 19, 2016

\begin{abstract}
Background. Computational fluid dynamics (CFD), a rapidly developing instrument with a number of practical applications, allows calculation and visualization of the changing parameters of airflow in the upper respiratory tract.
\end{abstract}

Objectives. The aim of this study was to demonstrate the advantages of CFD as an instrument for noninvasive tests of the larynx in patients who had undergone surgical treatment due to bilateral vocal fold paralysis.

Material and methods. Surface measurements of the glottic space were made during maximum adduction of the vocal folds. Additionally, the following spirometric parameters were determined: forced vital capacity (FVC), forced expiratory volume in the first second (FEV1), and peak expiratory flow (PEF) rate. Based on the measurements, commercial mesh generation software was used to develop a geometrical model of the glottic space. The computations were carried out using a general purpose CFD code. The analysis included patients who were surgically treated for BVFP in the authors' department between 1999 and 2012. The study group consisted of 22 women (91.67\%) and 2 men (8.33\%).

Results. It was observed that the pressure drop calculated for free breathing depends on the area of the glottis and is independent of its shape. Importantly, for areas below approx. $40 \mathrm{~mm}^{2}$, a sudden rise occurred in the resistance to flow; for the smallest glottic areas studied, the pressure drop was almost 6 times higher than for an area of $40 \mathrm{~mm}^{2}$. Consequently, in cases of areas below $40 \mathrm{~mm}^{2}$ even minor enlargement of the glottic opening can lead to a marked improvement in breathing comfort.

Conclusions. Computational fluid dynamics is a useful method for calculating and visualizing the changing parameters of airflow in the upper respiratory tract.

Key words: CFD, bilateral vocal fold paralysis, air flow

DOI

10.17219/acem/64235

\section{Copyright}

Copyright by Author(s)

This is an article distributed under the terms of the

Creative Commons Attribution Non-Commercial License

(http://creativecommons.org/licenses/by-nc-nd/4.0/) 
The larynx is an organ that fulfills vital functions. It is part of the upper respiratory tract, a speech organ and a protective barrier for the lower respiratory tract against aspiration and choking on food. ${ }^{1}$ Impaired morphology of the larynx or the mobility of the structures result in the impairment of at least one of the functions of the organ. Bilateral vocal fold paralysis (BVFP) is an example of a condition in which both airway hydrodynamics and phonation are affected. It is a symptom of bilateral damage to the recurrent laryngeal nerve (RLN), which is responsible for the mobility of the abductor and adductor muscles of the glottic space. ${ }^{2,3}$ The most common cause of RLN damage is surgical intervention in either the neck or the chest (thyroid gland, cardiac and thoracic surgical procedures). ${ }^{2,4}$ Shortness of breath, especially during the inspiratory phase, is a symptom accompanying BVFP, which can be concurrent with stridor and hoarseness. ${ }^{5}$ Some patients adapt quickly to diminished glottic space, while others require immediate tracheotomies followed by glottis-widening surgery. ${ }^{6}$ In BFVP, 2 categories of reconstructive surgical procedures are performed, i.e. surgery which models the glottic space and procedures that change the glottic space permanently by removing some laryngeal structures. ${ }^{7}$ Improvement of ventilation is almost always associated with deterioration of the quality of the patient's voice. ${ }^{8}$

Currently, 2 main types of surgical procedures widening the glottic space are performed at the Department of Otorhinolaryngology and Laryngological Oncology, Medical University of Silesia in Zabrze (Poland): arytenoidectomy with posterior cordectomy using a $\mathrm{CO}_{2}$ laser, and laterofixation with the Lichtenberger needle carrier. The aim of an arytenoidectomy with posterior cordectomy is to widen the glottis by removing the posterior part of the vocal fold and the arytenoid on the same side.

In everyday practice, there is no test that could determine the morphology of the larynx and the dynamic properties of the airflow, such as air velocity, pressure and resistance in the upper respiratory tract. Moreover, some tests are invasive, causing the patient's discomfort. Computer simulation with computational fluid dynamics (CFD) is an alternative to invasive tests. This method allows non-invasive calculation and visualization of the dynamically changing parameters of the laryngeal airflow.

Computational fluid dynamics is a rapidly developing instrument with a number of practical applications. CFD simulations have been used for years in aerodynamics, engineering, hydraulics, meteorology, construction and a number of other fields. ${ }^{9}$ In medicine it has been used primarily in pulmonology and cardiology - areas in which the dynamic properties of gas and liquid play an important role in the proper functioning of the body.

The aim of the present study was to demonstrate the advantages of CFD as an instrument for non-invasive tests of the larynx in patients treated surgically due to BVFP.
Because of the complexity of the method, its implementation requires cooperation between medical doctors and engineers, and this was the case in this study as well.

\section{Material and methods}

The study included patients who were surgically treated for BVFP in the authors' department between 1999 and 2012. The study group consisted of 22 women (91.67\%) and 2 men (8.33\%). The average age of the patients was 66.13 years (range: $49-82$ ). In 20 cases, BVFP occurred as a complication following a thyroidectomy (83.33\%). In 3 cases, the reason for BVFP was prolonged intubation (12.5\%), and in 1 case the cause remained unknown (4.16\%). These patients underwent arytenoidectomy with posterior cordectomy. The control group was comprised of 3 women and 2 men (mean age 33.2 years).

The study protocol was approved by the local Bioethics Committee (decision no. KB/157/12, October $2^{\text {nd }}, 2012$ ).

Laryngeal examinations were performed during routine visits to the laryngological outpatient clinic. Video images of the glottis during phonation were recorded using indirect laryngoscopy - a Karl Storz Telecam 20212030 video laryngoscope (Karl Storz GmbH \& Co., Tuttlingen, Germany) and a monitor. The data was analyzed using IRIS 2.2.0 software (MediCom, Wrocław, Polska) While recording the video of the glottis during phonation, a freeze-frame of the maximum vocal fold adduction was captured. Surface measurements of the glottic space were made during the maximum adduction of the vocal folds. In order to calibrate the measurements, the "length of the glottis" was taken as a constant parameter, as proposed by Eckel and Sittel, who reported measurements of 20 larynges obtained from fresh corpses. ${ }^{10}$ Among the parameters measured, the length of the glottis, defined as the distance from the base of the vocal folds to the mucosa of the posterior commissure, is regarded as particularly reproducible. This distance was $17.55 \pm 0.92 \mathrm{~mm}$ and $20.09 \pm 3.07 \mathrm{~mm}$ in women and men, respectively.

Subsequently, the contours of the glottic space were outlined using the IRIS program and the following geometric parameters were calculated: $\mathrm{O}$ - the circumference of the outlined figure $(\mathrm{mm}) ; \mathrm{S}$ - the surface area of the outlined figure $\left(\mathrm{mm}^{2}\right)$; and D - the length of the segment connecting 2 most distant points on the perimeter $(\mathrm{mm})$. The width of the glottic space was measured at the largest point of the lumen.

Additionally, the following spirometric parameters were determined: forced vital capacity (FVC), forced expiratory volume in the first second $\left(\mathrm{FEV}_{1}\right)$ and peak expiratory flow (PEF) rate. Since it was not possible to compare the airflow before and after surgery, appropriate imaging studies and spirometry were performed for 5 healthy controls to compare with the results from the patients.

Based on the measurements, Gambit 2.4.6 (Ansys Inc., 
Canonsburg, USA) commercial mesh generation software was used to develop a geometrical model of the glottic space. Since the larynx has an irregular structure, some simplifications had to be made in formulating the model (Fig. 1). The shape of the glottic opening was analyzed in both postoperative patients and the controls during the largest abduction of the vocal folds. The glottis was represented by means of straight lines and curves in the Cartesian coordinate system. The shapes were approximated with isosceles and right triangles, and with semiellipses. The surface areas obtained were $18-64 \mathrm{~mm}^{2}$ for the postoperative patients and $48-143 \mathrm{~mm}^{2}$ for the controls. The regions above and below the glottic opening were modeled as a cylinder with a diameter of $25 \mathrm{~mm}$ and a length of $50 \mathrm{~mm}$. It was assumed that these regions were the same for all patients. The length of the section analyzed was $102 \mathrm{~mm}$. Based on this geometrical model, a numerical grid comprising about 54,000 cells was generated. The actual number of grid elements depended on the glottic area. Although the assumed 3-dimensional geometry is simplified compared with images yielded by computed tomography, it is quite sufficient for the purpose of analyzing the effect of the glottic shape on airflow hydrodynamics. ${ }^{11}$ The boundary conditions associated with the grid were as follows: no slip of the fluid at the wall, flat velocity profile at the inlet, and no velocity gradient across the outlet. All the results were obtained during the expiratory phase, so the inlet quantities are those on the tracheal side of the glottis.

The computations were carried out using the general purpose CFD code Fluent (Ansys Inc., Canonsburg, USA). A steady flow of air was assumed with the atmospheric pressure prevailing in the larynx (101.325 Pa). The initial conditions were defined by the airflow rate, and the minimum value was set at $5 \mathrm{~L} / \mathrm{min}$ (tidal volume, TV). The maximum value of this flow was calculated separately for each patient, based on the PEF rate obtained using spirometry. These velocities correspond to turbulent flow. Laminar flow occurs at relatively low flow rates, and the velocity profiles become parabolic. For turbulent flow, the fluid elements rotate in various directions rather than moving parallel to one another, which leads to flattening of the velocity profiles. The mode of the flow (turbulent or laminar) is determined by the Reynolds number (Re): below $\operatorname{Re}=2.400$, the flow is laminar, while above this value the flow becomes turbulent. In the present study, the transition occurred at an inlet velocity of about $1.5 \mathrm{~m} / \mathrm{s}$. Therefore, for $\mathrm{w}<1.5 \mathrm{~m} / \mathrm{s}$, the laminar model was used in the calculations, whereas for the velocities exceeding $1.5 \mathrm{~m} / \mathrm{s}$, the computations were done by employing the turbulence model $\mathrm{k}-\varepsilon$ standard, available in the Fluent software package. The convergence criterion was based on the normalized sum of numerical residues and was set at $10^{-3}$.
Fig. 1. Geometrical model: a) measurement of the area of the glottic opening; b) numerical grid; c) simplified geometrical representation of the larynx and the glottic opening

a)

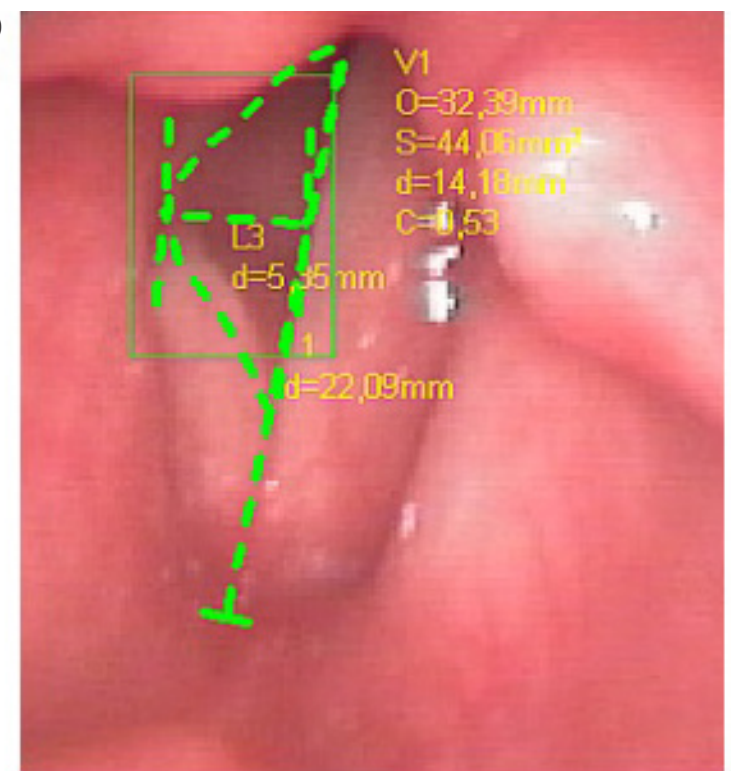

b)
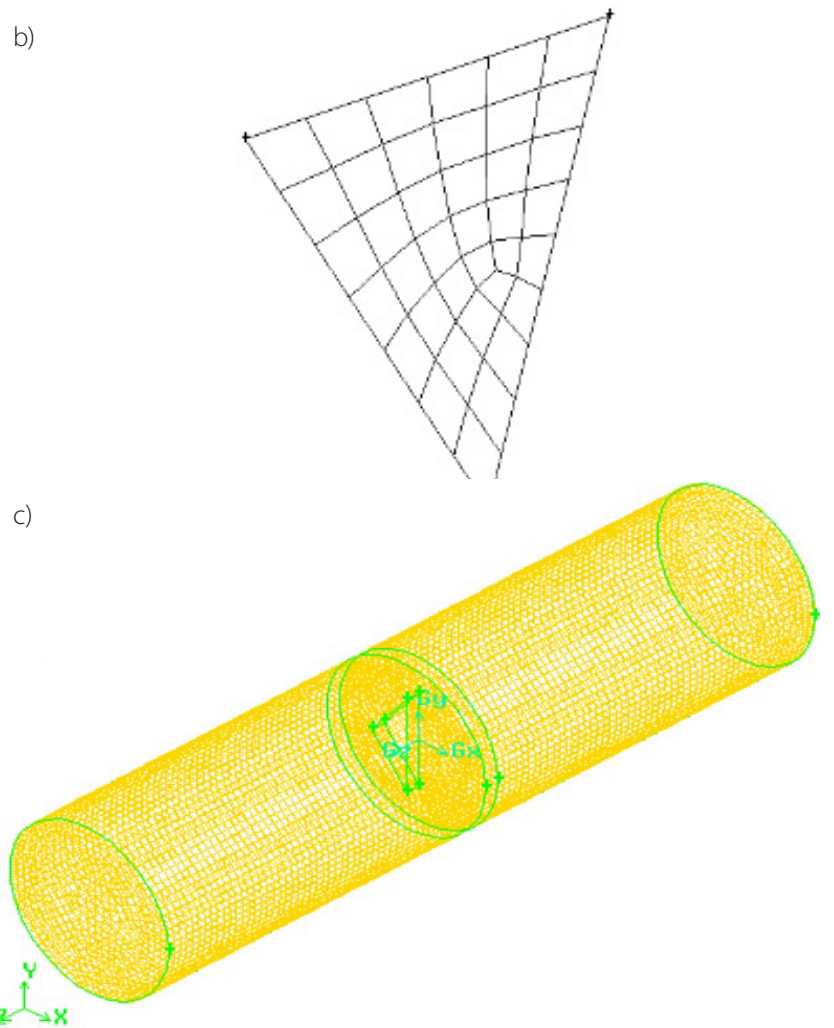

\section{Results}

For velocities associated with normal, unobstructed breathing $(\mathrm{w}=0.169 \mathrm{~m} / \mathrm{s})$, the lowest pressure drops were obtained for the controls $(0.5-4.1 \mathrm{~Pa})$. The values documented postoperatively were higher, ranging from $2.4 \mathrm{~Pa}$ to $29.7 \mathrm{~Pa}$. Figure 2 illustrates the results. It can be observed that the pressure drop calculated for free breath- 
Fig. 2. Pressure drop $(\triangle P)$ vs the area of the glottic opening $(S)$ at an inlet velocity of $\mathrm{w}=0.169 \mathrm{~m} / \mathrm{s}$. Solid symbols - postoperative patients; outline symbols - controls

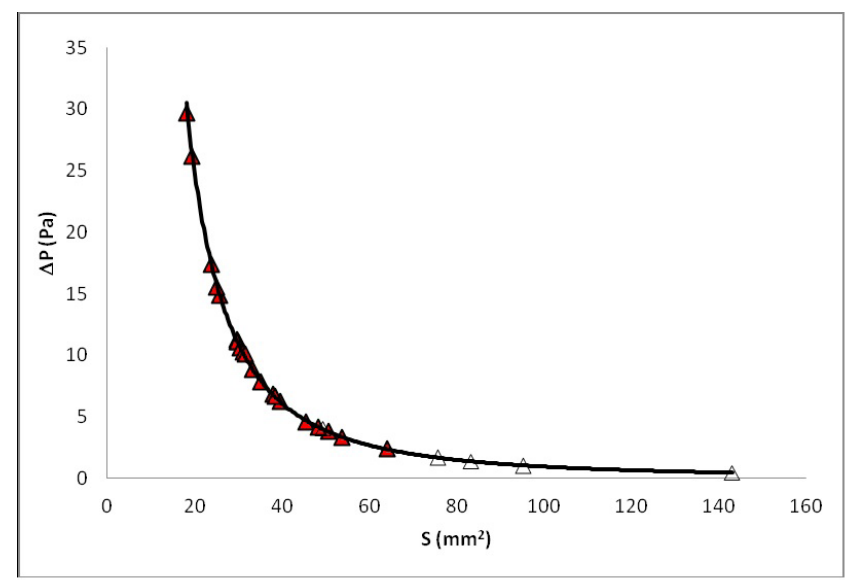

Fig. 3. Pressure drop vs the area of the glottic opening for the various inlet velocities

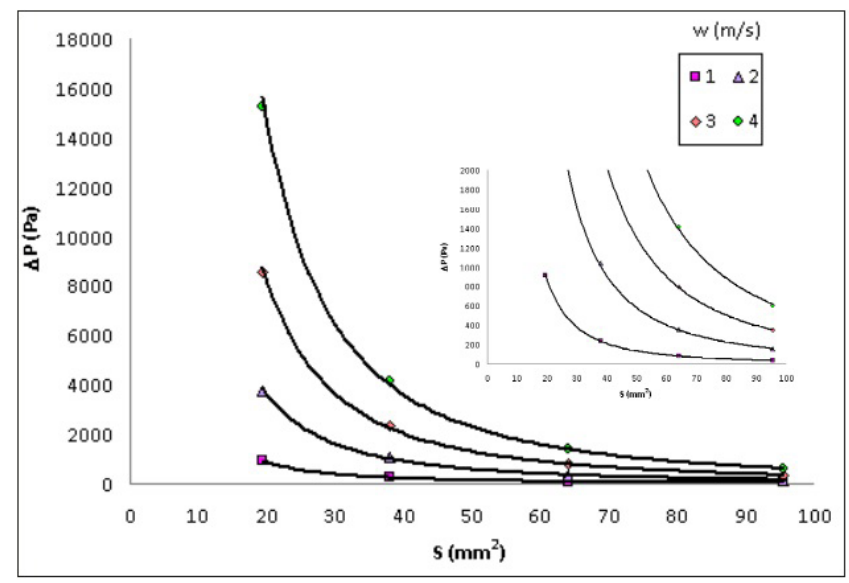

ing depends on the area of the glottis and is independent of its shape. Importantly, for areas below approx. $40 \mathrm{~mm}^{2}$, a sudden rise occurred in the resistance to flow - for the smallest glottic areas studied, the pressure drop was almost 6 times higher than for an area of $40 \mathrm{~mm}^{2}$. Consequently, in cases of areas lower than $40 \mathrm{~mm}^{2}$ even minor enlargements of the glottic opening over this range may lead to a marked improvement in breathing comfort. Conversely, above $40 \mathrm{~mm}^{2}$ the pressure drops are lower than $7 \mathrm{~Pa}$, and increases in the glottic area have a relatively small effect on breathing. Furthermore, as shown in Fig. 3, the limiting area of the glottis grows as the inlet velocity increases, finally reaching values matching those of the controls.

The pressure drop over the glottis was correlated with the area of the opening, and the following relationship was calculated: $\Delta \mathrm{P}=1.4315\left(\mathrm{Q}^{2} / \mathrm{S}^{2}\right)$, with $\mathrm{R}^{2}=0.99$, where $\Delta \mathrm{P}$ represents the pressure drop across the glottis $(\mathrm{Pa})$, $\mathrm{Q}$ is the airflow rate $\left(\mathrm{m}^{3} / \mathrm{s}\right)$, and $\mathrm{S}$ is the area of the opening $\left(\mathrm{m}^{2}\right)$. This correlation is quite general in the sense that it is possible to quantify a decrease in the pressure drop following an enlargement of the glottic area without the necessity of using CFD simulations. Noticeably, the present results are consistent with both experimental and CFD data published previously. ${ }^{12,13}$

The effect of the glottic area on the maximum air velocity in the laryn $x$ with inlet velocity $\mathrm{w}=0.169 \mathrm{~m} / \mathrm{s}$ was also analyzed. For a given flow, mass flow rates through the various openings are identical. Therefore, if the opening area is smaller, the linear velocity of the flow increases so that the mass of air passing through the larynx in a unit of time remains constant. This velocity is the highest at the smallest cross-sectional area of the larynx. Maximum velocities $\left(\mathrm{w}_{\max }\right)$ are shown in Fig. 4 as a function of the area (S). The maximum velocity depends not only on the area of the glottic opening but also, to a certain extent, on its location within the larynx. Following partial arytenoidectomy with posterior cordectomy, the glottic area was unilaterally enlarged. Consequently, the opening became asymmetrical, which led to some minor differences in velocities for the same areas of the opening. Again, for areas below about $40 \mathrm{~mm}^{2}$, there is a visible increase in the maximum velocity, albeit less pronounced than in the case of $\Delta \mathrm{P}$. For areas between 20 and $40 \mathrm{~mm}^{2}$, $\mathrm{w}_{\max }$ increased from 2.5 to $5 \mathrm{~m} / \mathrm{s}$.

The measured PEF rates were $1.22-6.59 \mathrm{~L} / \mathrm{s}$ for postoperative patients and 4.1-12.7 L/s for the controls. The calculated pressure drops across the glottis for 3 different ranges of PEF (expressed as corresponding inlet velocities) are shown in Fig. 5 as a function of the glottic area. The function illustrates that $\triangle \mathrm{P}$ depends on both PEF and $\mathrm{S}$. It should be noted that patients with the same opening area usually had different PEF values during spirometry.

Figure 6 shows a comparison between the local pressure and velocity fields in the larynx for a selected postoperative patient $\left(\mathrm{S}=31.6 \mathrm{~mm}^{2}\right)$ and a control subject $\left(\mathrm{S}=48.3 \mathrm{~mm}^{2}\right)$ for the same value of PEF $(4.1 \mathrm{~L} / \mathrm{s})$. Due to the reduction in the area available for the flow, the pressure in the larynx increases before the glottis and decreases on the other side of the opening. The pressure drops are $24 \mathrm{kPa}$ and $10.3 \mathrm{kPa}$, respectively. The highest pressure drops across the glottis occur in the corners of the glottic opening. As for the velocity field, it can be noted that narrowing generates a considerable temporary increase in the air velocity. For a postoperative patient, this momentary velocity was as high as $163 \mathrm{~m} / \mathrm{s}$, whereas for a healthy subject it was $112 \mathrm{~m} / \mathrm{s}$.

\section{Discussion}

Damage to the RLN during surgical intervention in the thyroid gland was the most common reason for BVFP in the patients in the present study ( 20 out of 24 cases). Three cases of BVFP due to prolonged intubation were noted; the cause of 1 case remains unknown. The majority of 
Fig. 4. Maximum air velocity in the larynx vs the area of the glottic opening for an inlet velocity of $w=0.169 \mathrm{~m} / \mathrm{s}$. Solid symbols postoperative patients; outline symbols - controls

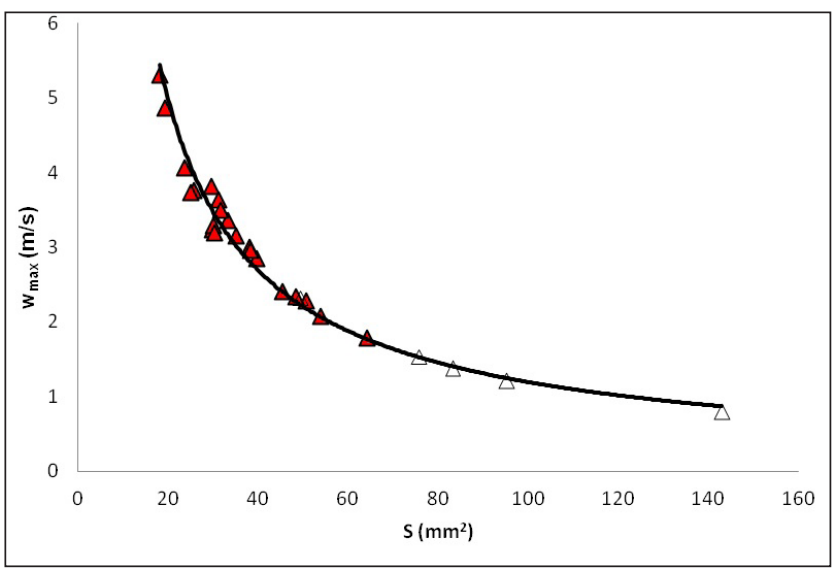

Fig. 5. $\triangle P$ vs $S$ for the various PEF values (expressed as inlet velocities)

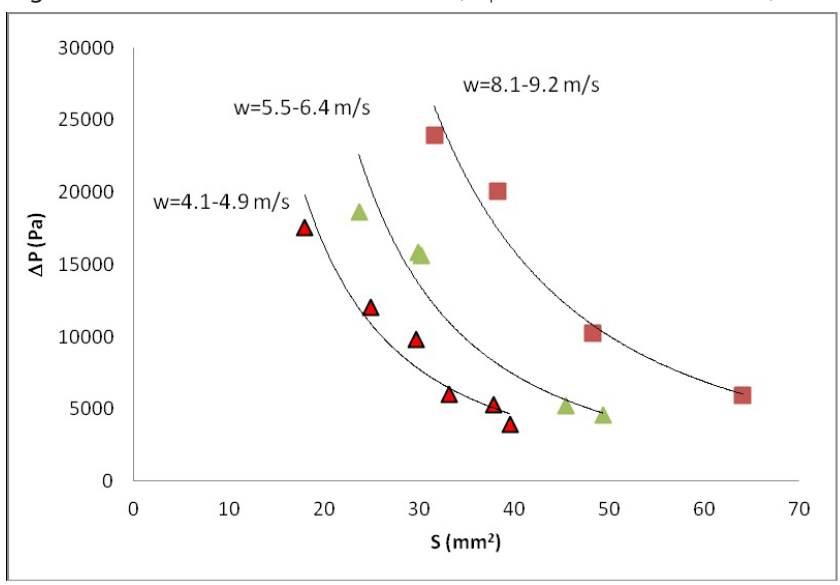

patients were women ( 22 out of 24 cases), which is consistent with other authors. ${ }^{14-18}$ Feehery et al. and Rosenthal et al. showed the highest percentage of paralysis due to the neoplastic process in the neck or the mediastinum. ${ }^{4,19}$ In contrast, Sharan et al. reported a predominance of men in their study, and Plouin-Gaudon et al. reported the same proportion of men and women. In both of those studies, damage to the RLN during thyroidectomy was the most frequent etiology. ${ }^{20,21}$ Dursun et al. reported an overwhelming inflammatory etiology of the paralysis, and a preponderance of women. ${ }^{22}$ The frequency of reported significant majorities of women is associated with the more frequent incidence of thyroid disease among women, and hence the necessity to perform thyroid surgery. ${ }^{23}$

During the flow of air across the glottis a pressure drop $(\Delta \mathrm{P})$ occurs, which is caused by perturbations of the flow. The pressure losses are caused by the resistance to the flow produced by the changing cross-section of the larynx. The pressure drop is an important parameter, covered extensively in a number of papers that discuss airflow in the upper respiratory tract. ${ }^{11-13,24-26}$ The calculations by means of the Fluid software yielded the values
Fig. 6. Local pressure $(a, b)$ and velocity $(c, d)$ fields in the larynx for the same PEF value in a selected postoperative patient $(a, c)$ and a healthy subject $(b, d)$

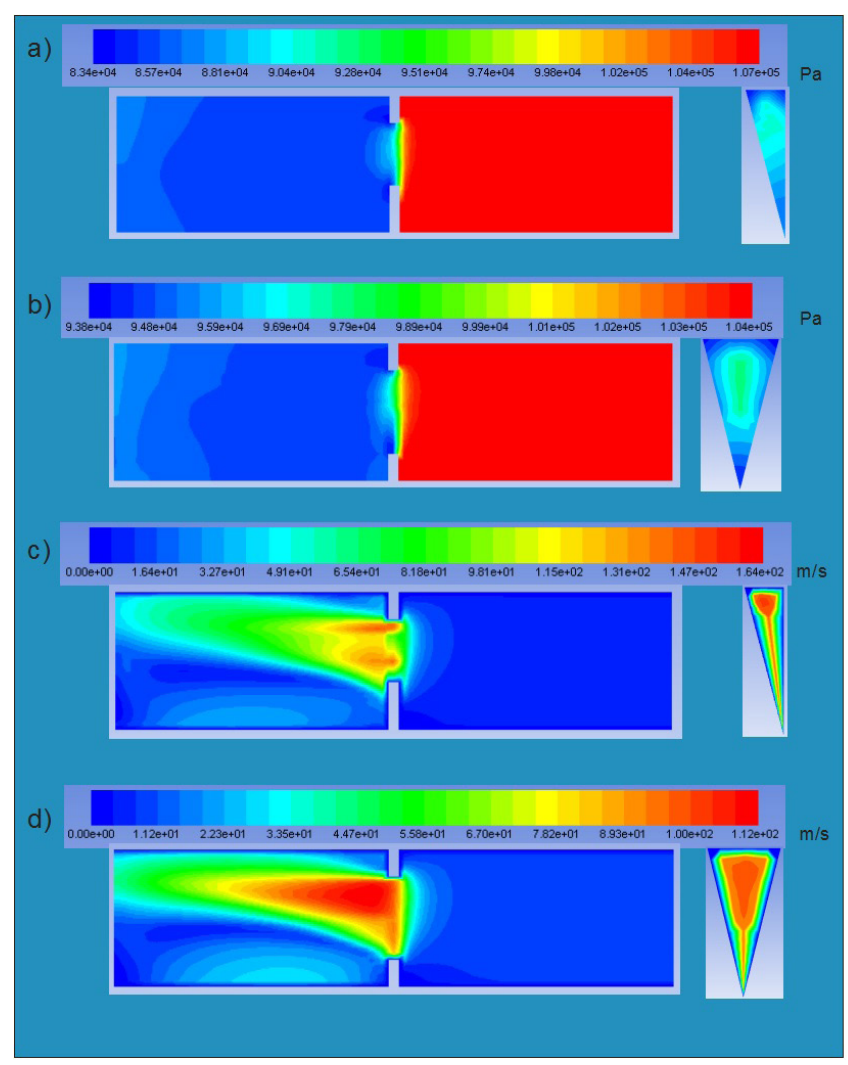

of the pressure drop over the glottic opening, as well as the local pressure and velocity fields in the larynx.

\section{Conclusions}

Computational fluid dynamics is a useful method that allows the changing parameters of the airflow in the upper respiratory tract to be calculated and visualized. This method comprises the core of the Fluent software package, which can be efficiently used to analyze various problems associated with normal or impaired breathing. This study presented simulations of airflow through the larynx in patients who had undergone laser arytenoidectomy with posterior cordectomy and in control subjects. The calculations were done for velocities ranging from those corresponding to tidal volume (TV) up to values coinciding with the PEF obtained from spirometry. It was determined that resistance to airflow, expressed as the pressure drop $\Delta \mathrm{P}$, depends on the area of the glottic opening and is virtually independent of its shape. During free breathing, a steep rise in $\Delta \mathrm{P}$ occurs for areas below about $40 \mathrm{~mm}^{2}$. It can be concluded that below this area even a minor enlargement of the glottis may significantly improve quality of breathing. Above $40 \mathrm{~mm}^{2}$ widening the glottic space begins to lose its therapeutic value. With increases in inlet velocities to the glottis, this boundary 
shifts toward larger values. Based on CFD analyses, it was possible to correlate $\Delta \mathrm{P}$ with the area of the glottic opening. This correlation is a useful instrument in evaluating the change in airway sufficiency resulting from the altered geometry of the glottis.

\section{References}

1. Sapundzhiev N, Lichtenberger G, Eckel HE, et al. Surgery of adult bilateral vocal fold paralysis in adduction: History and trends. Eur Arch Otorhinolaryngol 2008;265:1501-1514.

2. Chen HC, Jen YM, Wang CH, Lee JC, Lin YS. Etiology of vocal cord paralysis. ORL J Otorhinolaryngol Relat Spec. 2007;69:167-171.

3. Bochenek A, Reicher M. Anatomia człowieka. Warszawa: Wydawnictwo Lekarskie PZWL;2010; vol 5:234.

4. Rosenthal LH, Benninger MS, Deeb RH. Vocal fold immobility: A longitudinal analysis of etiology over 20 years. Laryngoscope. 2007;117:1864-1870.

5. Kennedy TL. Surgical complications of thyroidectomy. Oper Tech Otolaryngol Head Neck Surg. 2003;14:74-79.

6. Hans S, Vaissiere J, Crevier-Buchman L, Laccourreye O, Brasnu D. Aerodynamic and acoustic parameters in $\mathrm{CO} 2$ laser posterior transverse cordotomy for bilateral vocal fold paralysis. Acta Otolaryngol. 2000;120:330-335.

7. Janczewski G. Otorynolaryngologia praktyczna. Gdańsk: Via Medica; 2007; vol 2:503.

8. Misiolek M, Ziora D, Namyslowski G, et al. Long-term results in patients after combined laser total arytenoidectomy with posterior cordectomy for bilateral vocal cord paralysis. Eur Arch Otorhinolaryngol. 2007;264:895-900.

9. Mylavarapu G, Mihaescu M, Fuchs L, Papatziamos G, Gutmark E. Planning human upper airway surgery using computational fluid dynamics. J Biomech. 2013;46:1979-1986.

10. Eckel HE, Sittel C. Morphometry of the larynx in horizontal sections. Am J Otolaryngol. 1995;16:40-48.

11. Gokcan MK, Kurtulus DF, Ustuner E, et al. A computational study on the characteristics of airflow in bilateral abductor vocal fold immobility. Laryngoscope. 2010;120:1808-1818.

12. Heenan AF, Matida E, Pollard A, Finlay WH. Experimental measurements and computational modeling of the flow field in an idealized human oropharynx. Exp Fluids. 2003;35:70-84.

13. Nithiarasu $P$, Hassan $O$, Morgan $K$, et al. Steady flow through a realistic human upper airway geometry. Int J Numer Meth Fluids.2008;57:631-651.

14. Dursun G, Göckan MK. Aerodynamic, acoustic and functional results of posterior transverse laser cordotomy for bilateral abductor vocal fold paralysis. J Laryngol Otol. 2006;120:282-288.

15. Pinto JA, Godoy LB, Marquis VW, Sonego TB, Leal CF. Bilateral vocal fold immobility: Diagnosis and treatment. Braz J Otorhinolaryngol. 2011;77:594-599.

16. Łuczaj J, Kosztyła-Hojna B, Rutkowski R, Rogowski M. Operacyjne poszerzenie szpary głośni z zastosowaniem lasera $\mathrm{CO}_{2} \mathrm{w}$ dysfonii porażennej. Pol Merk Lek. 2008;143:385-391.

17. Motta $S$, Moscillo L, Imperiali M, Carra P, Motta G. $\mathrm{CO}_{2}$ laser treatment of bilateral vocal cord paralysis in adduction. ORL J Otorhinolaryngol Relat Spec. 2003;65:359-365.

18. Misiołek M, Namysłowski G, Warmuziński K, Karpe J, Rauer $R$, Misiołek $\mathrm{H}$. The influence of laser arytenoidectomy on ventilation parameters in patients with bilateral vocal cord paralysis. Eur Arch Otorhinolaryngol. 2003;260:381-385.

19. Feehery JM, Pribitkin EA, Heffelfinger RN, et al. The evolving etiology of bilateral vocal fold immobility. J Voice. 2003;17:76-81.

20. Sharan CJ, Bahadur S, Handa KK, Thakar A, Pande JN. Changes in ventilatory function following surgery for bilateral abductor paralysis. Indian J Otolaryngol Head Neck Surg. 2009;61:208-212.

21. Plouin-Gaudon I, Lawson G, Jamart J, Remacle M. Subtotal carbon dioxide laser arytenoidectomy for the treatment of bilateral vocal fold immobility: Long-term results. Ann Otol Rhinol Laryngol. 2005;114:115-121.
22. Dursun G, Sataloff RT, Spiegel JR, Mandel S, Heuer RJ, Rosen DC. Superior laryngeal nerve paresis and paralysis. JVoice. 1996;10:206211.

23. Łacka K, Fraczek MM. Classification and etiology of hyperthyroidism. Pol Merkur Lek. 2014;213:206-211.

24. Brouns M, Jayaraju ST, Lacor $C$, et al. Tracheal stenosis: A flow dynamics study. J Appl Physiol. 2007;102:1178-1184.

25. Cisonni J, Van Hirtum A, Pelorson X, Willems J. Theoretical simulation and experimental validation of inverse quasi-one-dimensional steady and unsteady glottal flow models. J Acoust Soc Am. 2008; 124:535-545.

26. Park JB, Mongeau L. Instantaneous orifice discharge coefficient of a physical, driven model of the human larynx. J Acoust Soc Am. 2007;121:442-455. 